\title{
Impact of structured pre-natal counselling on early initiation of breast feeding and adherence to exclusive breast feeding: a comparative interventional study
}

\author{
Hiral B. Koli, Mudra Gopidas Nair, Maitri C. Shah*
}

Department of Obstetrics and Gynecology, Baroda Medical College, Vadodara, Gujarat, India

Received: 19 April 2021

Accepted: 27 May 2021

\section{*Correspondence:}

Dr. Maitri C. Shah,

E-mail: maitrishah.gynec@gmail.com

Copyright: () the author(s), publisher and licensee Medip Academy. This is an open-access article distributed under the terms of the Creative Commons Attribution Non-Commercial License, which permits unrestricted non-commercial use, distribution, and reproduction in any medium, provided the original work is properly cited.

\begin{abstract}
Background: The importance of early initiation of breast feeding (EIBF) and exclusive breastfeeding (EBF) is widely recognized, but the optimum rates have not been attained due to several factors. One of the important factors is the lack of adequate knowledge of women regarding breastfeeding.

Methods: This comparative intervention study was conducted in the obstetric OPD and postnatal wards of tertiary care hospital of central Gujarat. This study included antenatal women between gestational age of 28 to 38 weeks who are visiting obstetric OPD at our institute and wanted to deliver at the same as cases (356 participants) and postpartum women who were delivered at this institute who have not taken antenatal care and counselling at this institute as control. Results: This study concluded that prenatal counselling regarding breast feeding had significant impact on the improvement of knowledge of women regarding EIBF and Exclusive breast feeding. Rate of EIBF and EBF was 91.85\% and $86.52 \%$ in case group which was significantly higher compared to the control group.

Conclusions: Prenatal structured counselling helps to raise the rate of EIBF and EBF
\end{abstract}

Keywords: EIBF, EBF, Counselling

\section{INTRODUCTION}

Breastfeeding is the tool which satisfies all the basic needs of a new-born baby starting from the filling the stomach to filling the heart by gaining the warmth of the mother. ${ }^{1}$ Numbers of benefits are there of breastfeeding. Promotion and Education of breastfeeding has become frontline service for antenatal and postnatal women. Breastfeeding practice gets affected by many factors like Social, cultural, biophysical, demographic and psychological. ${ }^{2}$

Early initiation of breast feeding is defined as initiation of breast feeding within one hour of birth. Exclusive breast feeding is recommended by WHO which states that breast feeding should be continued for 6 months exclusively and followed by continued breastfed alongside introduction of solid food. ${ }^{3}$
In India, breastfeeding is being practised but the rates of EIBF, EBF and time of initiation of supplementary feeding is far from desirable. As per the national family health survey 4 (NHFS 4 ) the rate of breast feeding is $25 \%$ at first hour and $39 \%$ at 6 months of postpartum age. ${ }^{4}$

Breastfeeding is beneficial for both mother and a baby. In a baby it reduces the incidence and severity of infectious diseases like diarrhoea, inflammatory bowel disease, respiratory tract infection, otitis media, urinary tract infection, eczema long term benefits in prevention of obesity, diabetes mellitus type 1 and 2, cardiovascular diseases, asthma and allergy to baby. ${ }^{5}$

In context to the maternal benefits of the breast feeding it reduces the risk of breast and ovarian cancers, osteoporosis, diabetes mellitus type 2 , helps to reduce the 
weight in post-partum period and raise the emotional bond between mother and child. ${ }^{6}$

Every year 5.6 million of infants die because of inadequate nutrition and one of the major reasons is lack of knowledge and awareness regarding EIBF and EBF. ${ }^{7}$

Rate of EIBF was found to be $60 \%$ at this institute. ${ }^{8}$ Fish bone analysis was done which suggested that major hindrance was at the level of people; due to lack to knowledge regarding general information, methods and benefits of breast feeding (Figure 1).

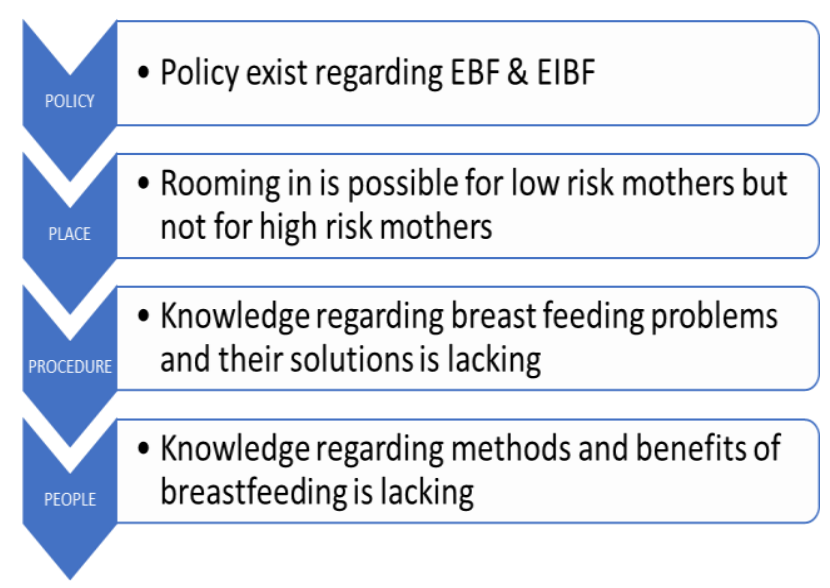

Figure 1: Root cause analysis fishbone.

The objective of this study is to evaluate the knowledge, attitude and practice of women regarding breast feeding visiting the antenatal OPD of this institute followed by giving structured counselling regarding the same. The rate of EIBF and EBF were compared between counselled group and non-counselled group.

\section{METHODS}

This study was conducted in the obstetrics outdoor department and postnatal wards of a tertiary care institute of Gujarat from April 2020 to November 2020. This was a comparative interventional study where all the antenatal women visiting antenatal OPD from gestational age of 28 to 38 weeks who agree to deliver at the same institute and agree to come for follow up after 1-month post-partum were eligible for participation in the study. Those who had given written informed consent were included in the study and served as cases. All other women delivered at our institute who has not taken any prenatal counselling session on breast feeding and who were agreeing to come for follow up after one-month post-partum were taken as control after taking their written informed consent. All PLHA women in whom breast feeding was not recommended were excluded before the delivery while critically ill mothers, women who had Premature or low birth weight babies or Babies requiring $\mathrm{KS}$ or IG feeding and babies with congenital malformation or serious illness who are not in a condition to tolerate breast feeds were excluded after delivery.

\section{Study period}

The study period was from April 2020 to November 2020.

\section{Sample size calculation}

The rate of EIBF in women delivering in labor room of our hospital is $60 \%$ and expected acceptance after intervention will be around $95 \%$. Considering these data, with precision $5 \%$ and confidence interval (CI) $95 \%$. The sample size is calculated to be minimum 356 each in control and case group.

\section{Study procedure}

After noting sociodemographic profile, obstetric history, menstrual history and any significant past history, open ended structured questionnaire were given as pre-test to evaluate the knowledge, attitude and practice regarding breast feeding. After pre-test, a structured counselling was done in form of interactive sessions with the help of power point presentation (which included importance of EIBF and EBF, techniques of breastfeeding, burping, about colostrum and how to solve breast feeding problems) in group of 10-15 women. Any doubt or query of women regarding breast feeding was resolved. All the women were given educational material in form of leaflet having information on EIBF and $\mathrm{EBF}$ including pictures regarding different positions for proper breast feeding in vernacular language after counselling. The same questionnaire was used for the post test of all participants. The difference between pre and post-tests was compared.

All these women were followed up after their delivery to know whether they actually had opted for EIBF or not. Mothers who delivered at our institute and who have not received any structured counselling session form control group. They were also interviewed for the adoption of EIBF. Both the groups were compared for the rate of the EBF.

All mothers were called for the follow up after one month where they were interviewed for the rate of EBF. Weight gain of the babies was noted. Mothers' confidence level was also analysed with help of pre-defined scoring system. All these details were compared between these groups.

Confidence level of the women following EIBF and EBFNot strongly confident: 1, Not confident: 2, Neutral: 3, Confident: 4, Strongly confident: 5

Rate of weight gain of a baby after one-month postpartum-The comparison of weight gain of a child was done by using WHO growth chart for boys and girls between birth to 1 month (z-score).

\section{Statistical analysis}

The data entry was done in the Microsoft excel spreadsheet and the final analysis was done with the use of statistical 
package for social sciences (SPSS) software version 21.0. The presentation of the categorical variables was done in the form of number and percentage $(\%)$. On the other hand, the presentation of the continuous variables was done as mean \pm SD and median values. The data normality was checked by using Kolmogorov-Smirnov test. The cases in which the data was not normal, we used non parametric tests. The following statistical tests were applied for the results: 1. The association of the variables which were quantitative in nature were analysed using Mann-Whitney test (for two groups) and Wilcoxon signed rank test was used for comparison between pre and post test score. 2 . The association of the variables which were qualitative in nature were analysed using Chi-Square test/Fisher's exact test. For statistical significance, $\mathrm{p}$ value of less than 0.05 was considered as significant.

The study protocols had been approved by institutional ethics committee on human research.

\section{RESULTS}

In present study, $73.60 \%$ of women belonged to age group 21-30 years. Mean value of age (years) of study subjects was $25.25 \pm 4.6$ with median $\left(25^{\text {th }}-75^{\text {th }} \%\right)$ of $25(22-28)$.

Mean value of pre-test score was $4.74 \pm 2.7$ while that of post test score was $11.41 \pm 0.88$ which showed statistically significant improvement in the test score after structured counselling (Table 1).

Education level of participants was significantly associated with higher rates of EIBF; it was maximum in graduate participants $(98.11 \%)$ while lowest $(74.32 \%)$ in illiterate group (Table 2).

$91.85 \%$ of cases were able to initiate BF within one hour compared to $71.35 \%$ of the control group which was statistically significant (Table 3 ).

Table 1: Comparison of pre and post test score survey of cases.

\begin{tabular}{|c|c|c|c|c|c|}
\hline Test scores & Mean \pm SD & Median $\left(25^{\text {th }}-75^{\text {th }} \%\right)$ & Range & P value & Test performed \\
\hline Pre-test score & $4.74 \pm 2.7$ & $4(3-7)$ & $1-12$ & \multirow{2}{*}{$<0.0001$} & \multirow{2}{*}{$\begin{array}{l}\text { Wilcoxon signed ranks } \\
\text { test; } z=16.215\end{array}$} \\
\hline Post test score & $11.41 \pm 0.88$ & $12(11-12)$ & $5-12$ & & \\
\hline $\begin{array}{l}\text { Difference } \\
\text { between pre and } \\
\text { post-test }\end{array}$ & $6.68 \pm 2.67$ & $7(5-9)$ & $0-11$ & - & - \\
\hline
\end{tabular}

Table 2: Association of various socio-demographic factors with EIBF.

\begin{tabular}{|c|c|c|c|c|c|}
\hline $\begin{array}{l}\text { Socio-demographic } \\
\text { characteristics }\end{array}$ & $\begin{array}{l}\text { EIBF, } \\
(\text { No) }(\%)\end{array}$ & $\begin{array}{l}\text { EIBF, } \\
(\text { Yes })(\%)\end{array}$ & $\begin{array}{l}\text { Total } \\
(\%)\end{array}$ & $\begin{array}{l}P \\
\text { value }\end{array}$ & $\begin{array}{l}\text { Test } \\
\text { performed }\end{array}$ \\
\hline \multicolumn{6}{|l|}{ Education level } \\
\hline Illiterate & $19(25.68)$ & $55(74.32)$ & $74(100)$ & \multirow{4}{*}{$<0.0001$} & \multirow{4}{*}{$\begin{array}{l}\text { Chi square test, } \\
39.631\end{array}$} \\
\hline $1^{\text {st }}$ to $10^{\text {th }}$ standard & $7(5.60)$ & $118(94.40)$ & $125(100)$ & & \\
\hline $11^{\text {th }}$ to $12^{\text {th }}$ standard & $2(1.92)$ & $102(98.08)$ & $104(100)$ & & \\
\hline Graduation & $1(1.89)$ & $52(98.11)$ & $53(100)$ & & \\
\hline
\end{tabular}

Table 3: Distribution of cases and control in reference to duration of initiation of breast feeding.

\begin{tabular}{|c|c|c|c|}
\hline $\begin{array}{l}\text { Establishment } \\
\text { breast feeding } \\
\text { by duration } \\
\text { (Hours) }\end{array}$ & $\begin{array}{l}\text { Cases, } \\
(n=356) \\
(\%)\end{array}$ & $\begin{array}{l}\text { Controls, } \\
(\mathbf{n}=356) \\
(\%)\end{array}$ & P value \\
\hline Within 1 & 327 (91.8) & $254(71.3)$ & \multirow{5}{*}{$<0.0001$} \\
\hline$>1$ to 12 & $19(5.34)$ & $56(15.73)$ & \\
\hline 13 to 24 & $7(1.97)$ & $29(8.15)$ & \\
\hline$>24$ & $3(0.84)$ & $17(4.78)$ & \\
\hline Total & $356(100)$ & $356(100)$ & \\
\hline
\end{tabular}

After structured counselling, the knowledge regarding various breast-feeding practices were improved significantly which was also reflected in its actual performance post-partum period. So, there was significant association between knowledge regarding various breastfeeding parameters and actual performance of these practices in the case group (Table 4).
Table 4: Association between knowledge of various breast-feeding parameters in antenatal period and actual practice in postpartum period (case group).

\begin{tabular}{|c|c|c|c|}
\hline $\begin{array}{l}\text { Breast } \\
\text { feeding } \\
\text { parameter }\end{array}$ & $\begin{array}{l}\text { Knowledge } \\
\text { regarding } \\
\text { particular } \\
\text { breast- } \\
\text { feeding } \\
\text { parameter, } \\
(\%)\end{array}$ & $\begin{array}{l}\text { Following } \\
\text { particular } \\
\text { breast-feeding } \\
\text { parameter in } \\
\text { postpartum } \\
\text { period, }(\%)\end{array}$ & P value \\
\hline EIBF & $333(93.54)$ & 327 (91.85) & \multirow{3}{*}{$<0.0001$} \\
\hline $\begin{array}{l}\text { Feeding } \\
\text { colostrum }\end{array}$ & 338 (94.94) & $323(90.73)$ & \\
\hline EBF & $330(92.7)$ & $308(86.52)$ & \\
\hline
\end{tabular}

\section{DISCUSSION}

Out of 26 million babies born in India every year, only about $45 \%$ are breastfed within the first one hour of life 
and $65 \%$ of children are exclusively breastfed in the first six months of life. ${ }^{4}$

Inadequate EIBF and EBF is directly related to morbidity and mortality in infants. Indian mothers face a lot of issues and are coping with the challenges related to their immediate environment. ${ }^{9}$ Major factors responsible for lower rates of EIBF and EBF in India is lack of adequate knowledge of mothers, maternal education and even socioeconomic factors. ${ }^{10,11}$

This study evaluated that age, religion, residence, occupational status, type of family was not associated with the rates of EIBF and EBF, but only educational status was significantly associated with higher rate of EIBF only. Patel et al in his study did not observe association of maternal education and maternal occupation with the rate of EIBF. ${ }^{2}$

The main objective of this study was to evaluate the rate of EIBF and EBF between counselled group and not counselled group, which was statistically significant in this study. The rate of EIBF in case and control group was $91.85 \%$ and $71.35 \%$ respectively and rate of EBF in onemonth post-partum was $86.52 \%$ and $67.98 \%$ respectively. Ahmad et al in his comparative study had similar results and concluded that breastfeeding counselling during antenatal period make women confident for EIBF and EBF resulting into positive infant outcome. ${ }^{12}$

Structured antenatal counselling about breast feeding was very effective in the present study which can be seen by a difference in the score of around 7 (pre-test score of 4.74 to post test score of 11.41). A study by Rea et al, evaluated the significant increment in the knowledge and skill regarding breast feeding by $23 \%$ after such counselling session. $^{13}$

By duration of initiation of breast feeding $91.85 \%$ mothers initiated within one hour of birth and total $97.19 \%$ initiated within 12 hours of birth in case group, while in control group proportion was $71.35 \%$ and $87.08 \%$ respectively. This difference was significant. In a study by Mullany et al, initiation of breast feeding within one hour was only $3.4 \%$ which was increased up to $56.6 \%$ after 24 hours. ${ }^{14}$

EBF rate was statistically higher in case group in compare to control group during first 1 month after birth. McFadden et al in their systemic review and meta-analysis came on inference that there was a significant effect of counselling interventions on any breastfeeding at 4 to 6 weeks and 6 months with greater positive impact but study done by McFadden et al concluded that counselling delivered at least 4 times postnatally is more effective than counselling delivered antenatally and/or less than 4 times. ${ }^{15}$

\section{CONCLUSION}

This comparative interventional study demonstrates that structured breastfeeding counselling in prenatal period can result in an increase in higher rates of EIBF and EBF. It raises the knowledge regarding various aspects of breastfeeding and also increases women's confidence level that help them to breast feed their babies with least assistance. This study shows that major barrier of nonadherence to EBF is women's perception of having insufficient breast milk secretion which raises the rates of supplementary feeding.

\section{Funding: No funding sources Conflict of interest: None declared \\ Ethical approval: The study was approved by the Institutional Ethics Committee}

\section{REFERENCES}

1. Tiwari K, Savarna N, Khanam I. A study on knowledge of breast feeding and effect of antenatal counseling on exclusive breast feeding in primigravida mothers. Int J Reprod Contraception, Obstet Gynecol. 2018;7(8):3311.

2. Patel D V, Bansal SC, Nimbalkar AS, Phatak AG, Nimbalkar SM, Desai RG. and Their Association with Morbidities in Children. Adv Prev Med. 2015;2015:1-9.

3. Khan J, Vesel L, Bahl R, Martines JC. Timing of breastfeeding initiation and exclusivity of breastfeeding during first month of life: effects on neonatal mortality and morbidity- a systemic review and meta-analysis. Maternal Child Health J. 2015;19(3):468-79.

4. Nishimura, H., Krupp, K., Gowda, S., Srinivas, V., Arun, A., \& Madhivanan, P. (2018). Determinants of exclusive breastfeeding in rural South India. Int Breastfeeding J. 2018;13:40.

5. Gulshan Ara, Mansura Khanam, Nowshin Papri, Baitun Nahar, Iqbal Kabir, Kazi Istiaque Sanin, Sihan Sadat Khan, Md Shafiqul Alam Sarker, Michael J Dibley, Peer Counseling Promotes Appropriate Infant Feeding Practices and Improves Infant Growth and Development in an Urban Slum in Bangladesh: A Community-Based Cluster Randomized Controlled Trial, Current Developments in Nutrition, Volume 3, Issue 7, July 2019.

6. Graffy JP. Evaluating breastfeeding support randomised control trial of support from breastfeeding counsellors. The university of Birminghm. 2001;355-70.

7. Nankunda JK, Ndeezi G, Semiyaga N. Individual peer counselling for exclusive breastfeeding in Uganda. Int Brastfeed J. 2006:45-67.

8. Nyoni S, Sweet L, Clark J, Ward P. A realist review of infant feeding counselling to increase exclusive breastfeeding by HIV-positive women in subSaharan-Africa. Internal breastfeeding J. 2019;1-12.

9. National Nutrition Month: Importance of Breastfeeding for Both Mother and Child. Swasth India. 2019:9.

10. Bhatt S, Parikh P, Kantharia N. Knowledge, attitude and practice of post-natal mothers for early initiation 
of breastfeeding in the obstetric wards of a tertiary care hospital of Vadodara city. National J Community Med. 2012;3(2):305-9.

11. Ogbo FA, Dhami MV, Awosemo AO, Olusanya BO, Olusanya J, Osuagwu UL et al. Regional prevalence and determinants of exclusive breastfeeding in India. Int Breastfeed J. 2019;14:20.

12. Randhawa A, Chaudhary N, Gill B S, Singh A. A population based cross-sectional study to determine the practice of breastfeeding among the lactating mothers of Patiala city. J Family Med Prim Care. 2019;8:3207-13.

13. Rea MF, Venancio SI, Martines JC, Savage F. Counselling on breastfeeding assessing knowledge and skills. Bull WHO. 1999;77:6.
14. 1Mullany LC, Katz J, Li YM, Khatry SK, LeClerq SC, Darmstadt GL, Tielsch JM. Breast-feeding patterns, time to initiation, and mortality risk among newborns in southern Nepal. J Nutr. 2008;138(3):599-603.

15. McFadden A, Siebelt L, Marshall JL, Gavine A, Girard LC, Symon A et al. Counselling interventions to enable women to initiate and continue breastfeeding: a systematic review and metaanalysis. Int Breastfeed J. 2019;14:42.

Cite this article as: Koli $\mathrm{H}$, Gopidas M, Shah M. Impact of structured pre-natal counselling on early initiation of breast feeding and adherence to exclusive breast feeding: a comparative interventional study. Int J Reprod Contracept Obstet Gynecol 2021;10:2699-703. 